\title{
Development of an Indigenously Made Diesel Fired Crucible Furnace
}

\author{
Tolulope Opeyemi Olukokun ${ }^{1}$, Adekunle Adefemi Adeyemi², Ismaila Olanrewaju Alabi ${ }^{3}$, Mudasiru Ariyo \\ Aderonmu $^{4}$ and Mutiu Olalekan Kareem ${ }^{5}$ \\ ${ }^{1}$ Department of Mechatronics Engineering, The Polytechnic Ibadan \\ South-Campus, Ibadan, Nigeria. \\ tolulope.olukokun@polyibadan.edu.ng \\ ${ }^{2}$ Department of Mechatronics Engineering, Federal University \\ Oye Ekiti, Ikole Ekiti Campus, Ekiti State Nigeria. \\ adefemi.adekunle@fuoye.edu.ng \\ ${ }^{3}$ Department of Mechanical and Automotive Engineering, Elizade University \\ Ilara-Mokin, Ondo State, Nigeria. \\ ismaila.alabi@elizadeuniversity.edu.ng \\ ${ }^{4}$ Department of Mechanical Engineering, The Polytechnic Ibadan \\ South-Campus, Ibadan, Nigeria. \\ aderonmu99@gmail.com \\ ${ }^{5}$ Department of Mechanical Engineering, The Polytechnic Ibadan \\ South-Campus, Ibadan, Nigeria. \\ kareemolalekan5@gmail.com
}

\begin{abstract}
The technological advancement of any nation have been influenced and uplifted by the extent to which it can usefully harness and convert its mineral resources. The productions of metal in foundries and in all human lives have become a general practice. This work deals with the design, fabrication and performance evaluation of a diesel-fired crucible furnace suitable for use both in the rural and urban areas for casting of different types of metals using indigenously sourced materials and technology. The components of furnace were furnace casing, crucible, furnace cover, burner housing, furnace cover stand, base stand and burner. Mild steel sheet was used for the fabrication of the furnace, while the other components needed for the design were selected based on functionality, durability, cost and local availability. Experimental tests were performed to evaluate the performance of the furnace. The average heating rate of $19.54^{\circ} \mathrm{C} / \mathrm{min}$ was recorded by the furnace and attained a temperature as high as $1420{ }^{\circ} \mathrm{C}$. The furnace also had a melting rate of $454.55 \mathrm{~g} / \mathrm{min}$ for Aluminium. The thermal efficiency of the furnace was determined to be $10.80 \%$. The low value was as result of the large energy wastage due to the type of insulator used in making the furnace wall. The furnace is environmental friendly without health hazards to the workers and can be moved from one place to another unlike the local one.
\end{abstract}

Keywords: Crucible furnace, Diesel fired, Average heating rate, Melting rate, Efficiency.

\section{Introduction}

Foundry deals with the melting of metals to their molten state which are eventually poured into a prepared mould to form a casting. The importance of a crucible furnace in the foundry industry is extremely high for melting metals and casting metallic wares such as; machines, machine parts and other related engineering materials [1]. The furnaces are stationary furnace and the crucibles (metal container) are withdrawn from them for pouring with the aid of crucible tongs. On a general note, furnaces are also employed in the heat treatment of metals in order to influence their mechanical and physical properties. Most industries that use logical methods for shaping metals rely on castings products whose productions are impossible without the furnace. Examples of such industries include Automobile, Machine tools, Aerospace, Electrical, Plumbing, Communication etc. [2]

However, the previously used crucible furnaces in local foundries are associated with the many problems like: Full exposure to heat and combustible products which are harmful to the body and health, loss of heat due to the open nature of the local furnace which leads to prolonged operational activities and amounts to undesired result. The previous open crucible 
furnaces contribute to ecological problems, global warming and environmental degradation due to high demand of wood for charcoal production, the process consumes large quantities of fuel (charcoal) due to its low combustion efficiency.

In a developing country like Nigeria, most foundry industries have suffered several set-backs such as lack of stable electrical power supply, high cost of importation of foreign furnaces, raw materials etc. which had resulted to low production output, loss of man hours, high cost of production, and in most cases, loss of jobs occasioned by closure of most of the industries. There are about 160 foundries in Nigeria at different stages of life and death conditions and they meet less than 5\% of Nigeria's demand for machine components and mechanical parts [3]. Most castings in Nigeria are imported, the poor performance of the manufacturing sector in Nigeria is indicative of the low state of the foundry industry of which majority are small-medium scale enterprises with an unsubstantial total productive cost and input to the upper limit of only between 5-20 million naira. This is quite very low compared to that in the US; put the market value of the annual casting shipments at 28-30 billion US dollars produced by approximately 3,200 foundries as reported in [4]. These myriad of problems therefore, necessitated this research work; "Development of an indigenously made diesel fired 30Kilograpm Capacity Crucible Furnace”.

\section{Crucible Furnace and Existing Works \\ 2.1. Crucible Furnace}

Components made from non-ferrous materials tend to display a marked decrease in performance level after years of service and have to be discarded. Re-melting and re-casting of scraps of such components helps to enhance availability of the component, [5]. Historically crucibles were made of clay, but they can be made of any material with higher temperature resistance than the substance they are designed to hold. The most commonly used furnaces may be classified according to the source of heat, type of work and working environment. It can be broadly divided into two classes:

i. Fuel fired furnaces (depending on the type of fuel, i.e. solid fuel, liquid fuel and gaseous fuel.

ii. Electrically heated furnaces (conversion of electrical energy into heat energy). Depending on the method of heating, electrical furnaces can be grouped into resistance, arc, induction, plasma and electron beam furnaces.

Thus, there are different types of Crucible Furnace as shown in fig. 2.1, these include:

a) The stationery pot: this is the simplest form of crucible furnace. The molten metal is ladle out directly for casting.

b) The lift- out pot: consist of a pot that can be lifted out of the furnace by means of a tongs for pouring.

c) The tilting pot: here the entire furnace is tilted to pour out the molten metal directly into the ladle or mould, in which the molten metal is transferred to the mould or ladle by mechanically tilting the crucible and furnace body [6].

The modes of firing crucible furnace are also represented in fig. 2.2. Thus, crucible furnace is applicable in annealing, heat treating, research \& development, melting, sintering ceramics, general purpose heating, thermal reactors, gold, silver and copper melting, etc.

\subsection{Existing Works on Crucible Furnace}

In most third world nations, one of the cheapest ways to melt non-ferrous metal commercially in a crucible furnace is by using combustion fuel (i.e. oxidation of fossil fuel). Furnace design may vary according to its function, heating duty performed, heating method applied or type of fuel used as reported by Olalere et al. [7]. The paper also reported the following: [8] improved on the gas fired crucible type method of melting by designing a coal fired crucible furnace. He observed that charcoal remains the most available fuel as coal is not available in many parts of the country. [9] did a study evaluating the performance of a charcoal-fired furnace for recycling aluminium scraps. The efficiency of the furnace was $11.5 \%$. This value was low as a result of the large quantity of energy wasted due to the open nature of the furnace. [10] designed electrically powered stationary pot crucible furnace for pyrolysis show and cased the benefits of electrically power furnaces but its cost of operation was exorbitant. [11] Investigated the use of kerosene crucible furnace in their work. The furnace was able to attained $750^{\circ} \mathrm{C}$. While this temperature was fairly sufficient for melting aluminium, it was inadequate for other non-ferrous metals. [12] worked on diesel fired stationary pot crucible furnace for both heat treatment and salt bath. [13] carried out a design and construction of an oil-fired crucible furnace. The study focused on ensuring a high efficiency in melting of aluminium, by effectively minimizing heat losses, and maximizing heat generation was motivated by this challenge. Thus, the documented works of fuels for combustion in crucible furnace has shown that the need to obtain a fuel that is readily available and cheap remains a major challenge plaguing the foundry business in Nigeria. 


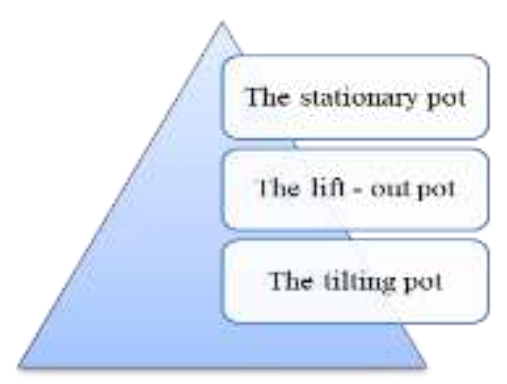

Fig 2.1 Types of Crucible Furnace.

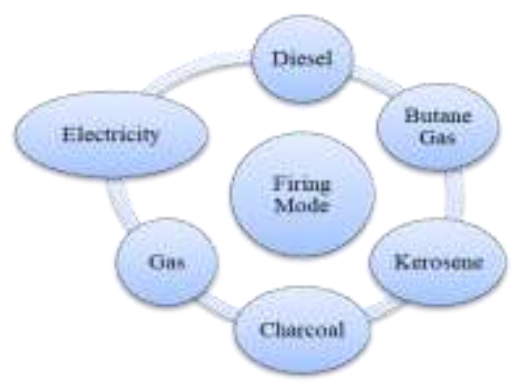

Fig 2.2 Modes of Firing Crucible Furnace.

\section{Methodology}

\subsection{Materials}

A large number of materials are available for engineering applications. The following were considered in this work: cost effectiveness, availability, high or low tensile, strength as may be required, rigidity and/or flexibility, heat and corrosion resistance, ductility, fatigue, toughness, weldability etc. The mild steel plate used for fabricating most components of the furnace is ductile, thus making it possible for it to be rolled, folded and bent without cracks or fractures.

\subsection{Component of a Crucible Furnace}

The component of a crucible furnace includes; the furnace casing, crucible, furnace cover, burner and its housing, base stand, chimney and the generating set. This is also represented in Fig 3.1.

\subsection{Working Principle}

The mode of operation of the diesel fired crucible furnace begins when the electric motor in the burner is connected to an electrical source, it drives the pump incorporated to it and suction occurs. The suction line attached to the burner drags diesel from the diesel tank through the burner and into the combustion chamber. Combustion process begins when a spark is introduced, and then the fuel (diesel) ignites. As this continues over time, the temperature rises gradually within and around the crucible, thereby melting its content. The furnace temperature can be read directly from an optical pyrometer through the chimney on the cover. When the crucible content is fully melted and is ready for pouring, the crucible is lifted out by means of a lifting tong, which is handled by two persons and then poured into the prepared mould cavity. The holes on the sides of the furnace are made to keep a balance between the pressure within and outside the system.

\subsection{Crucible Furnace Fabrication}

The crucible furnace was designed majorly to melt Aluminium, Brass, Cast Iron, Magnesium and any other metal with melting point below. Some of the equipment used in fabricating the various parts of the furnace is as follows: Folding/rolling machine, drilling machine, welding machine, cutting tools and marking/Measuring tools etc.

A. Furnace casing: The mild steel sheet was selected for the fabrication of the furnace casing because of its availability, relative light weight, good strength, excellent formability, weldability, availability and low purchase cost. The furnace casing houses all the components of the furnace including: fire bricks (clay) and lining, the burner and the crucible. 


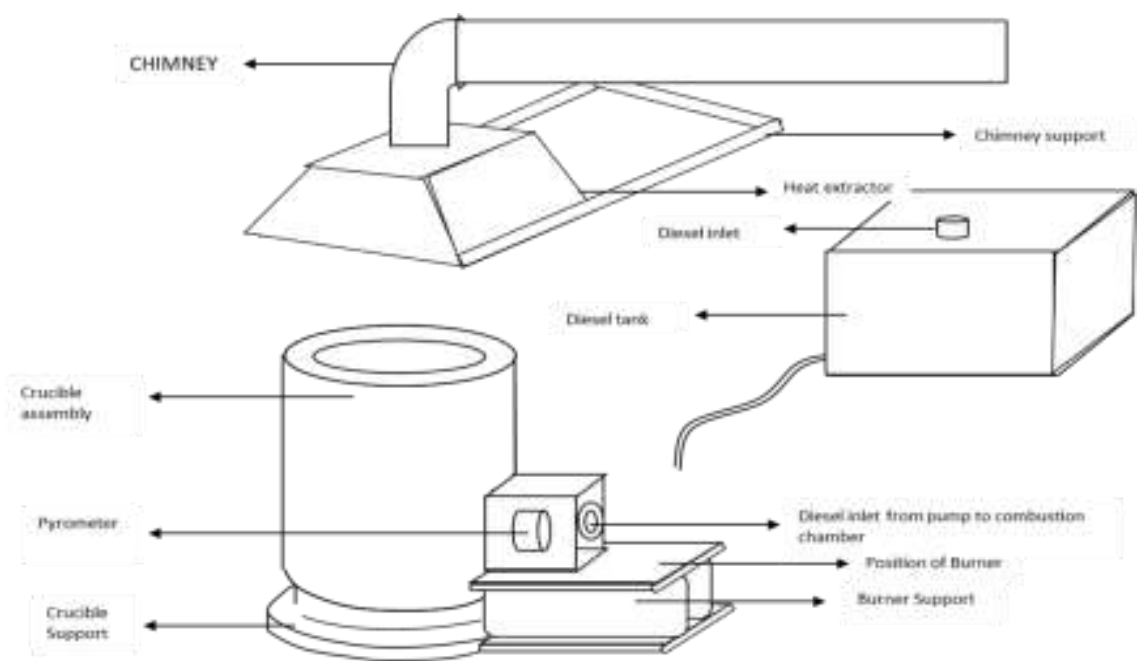

Fig. 3.1: Pictorial Representation of a Crucible Furnace.

B. The Crucible: The crucible is a cylindrical shaped container placed in the inner cavity (heating chamber) of the furnace. Its function is to accommodate the charge to be melted in the heating chamber of the furnace. The design is made to ensure that the charge to be melted is not in direct contact with the combustion gases but to serve as a medium to conduct heat generated from the combustion chamber which is transferred by convection to the charge. For this reason, the pot is made from chromium based steel which has high heat resistance, high strength and good thermal conductivity since it is exposed to direct heating. The pot which is in form of frustum has the following dimensions $5 \mathrm{~mm}$ thickness, $300 \mathrm{~mm}$ upper diameter, $180 \mathrm{~mm}$ lower diameter and $500 \mathrm{~mm}$ height. C.

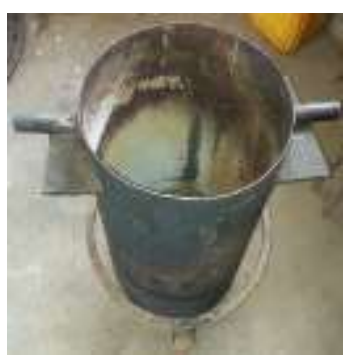

(a) Crucible Pot
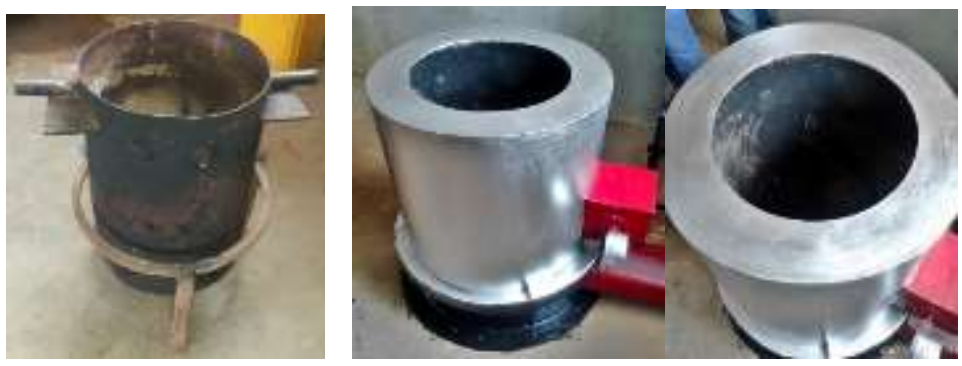

(b) Fabricated Crucible Furnace

D. Furnace cover: The cover was made from the $3 \mathrm{~mm}$ thick steel, it was rolled into a cylinder of $310 \mathrm{~mm}$ diameter, $90 \mathrm{~mm}$ height with a hole of $200 \mathrm{~mm}$ which serves as the exhaust.

\subsection{Other Specifications}

a. Refractory lining: The refractory lining for the furnace was made by mixing Refractory cement (Durax) was mixed with sodium silicate $\mathrm{Na}_{2}\left(\mathrm{SiO}_{2}\right)$ in the proportion of 1 Litre of $\mathrm{Na}_{2}\left(\mathrm{SiO}_{2}\right)$ to a bag of Durax of weight $25 \mathrm{~kg}$. The thoroughly blended mixture was used in lining the furnace which involves three stages.

b. Flooring: This was done by first making the surface of the base of the furnace wet with a mixture of water and sodium silicate before pouring a very thin layer $(2 \mathrm{~mm}$ thick) of the refractory mixture before arranging fire bricks into the base of the furnace. The mixture of the Castable refractory and sodium silicate then poured on it and allowed to set. 

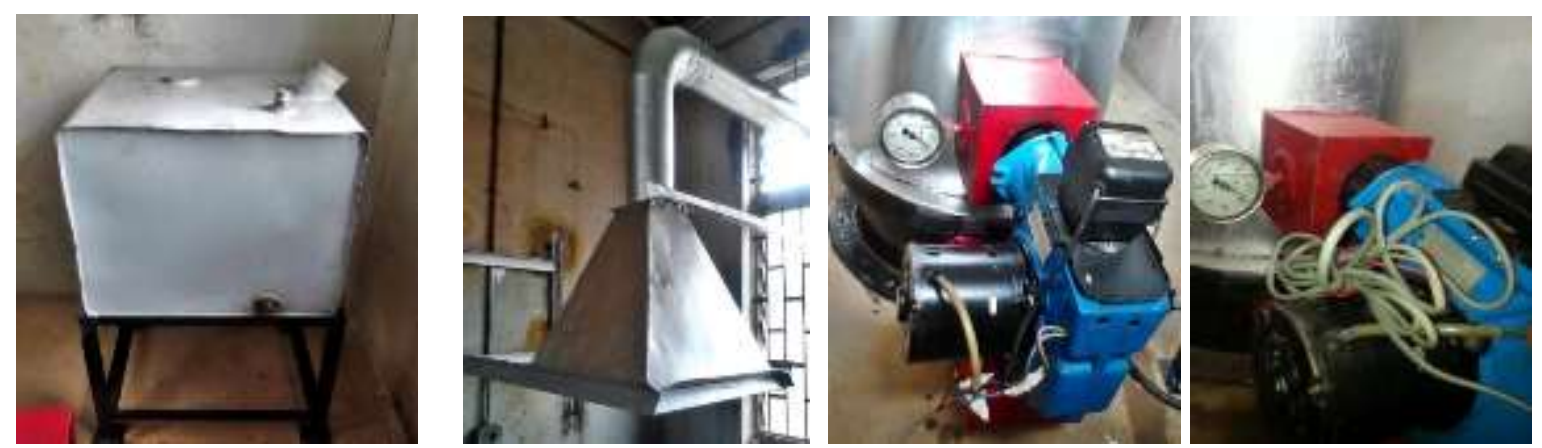

(c) Fabricated Diesel Tank (d) Fabricated Chimney (e) Burner assembly with pyrometer

Fig. 3.2: Crucible furnace components.

c. Flooring: This was done by first making the surface of the base of the furnace wet with a mixture of water and sodium silicate before pouring a very thin layer ( $2 \mathrm{~mm}$ thick) of the refractory mixture before arranging fire bricks into the base of the furnace. The mixture of the Castable refractory and sodium silicate then poured on it and allowed to set.

d. Drying: The furnace body is then allowed to dry for 28 days and any crack was duly observed and repaired as it dried.

e. Assembly: The parts assembled include: The casing, cover, the crucible stands, crucible, the cover stands and the burner. The cover stand which has a support for the cover and serves as a holder for the cover is first welded to the body of the furnace body before the cover is carefully placed in an anchor and it is held in place using a pin. Then the burner is placed in the $50 \mathrm{~mm}$ hole drilled in the burner housing at an angle 450 on the horizontal plane. The assembled diesel fired crucible furnace and its drawings are shown in Fig. 3.3.

f. Regulation of the Furnace Temperature: The temperature of the furnace can be regulated by simply controlling the air/fuel mixture content. It is done by opening or closing slightly the control valves of either or both of air and diesel fuel, to regulate the air-fuel ratio or the amount of air and diesel fuel entering the combustion chamber. The furnace temperature can be determined during melting operations by various means such as; focusing the pyrometer on the flame from the furnace through the chimney provided at the top of the cover and the temperature is read directly. Secondly through incorporation of a thermocouple in the furnace designed to enable the temperature of the metal during melting to be monitored. A traditional method which is not safe is by dipping a long iron rod into the molten metal to check if it has completely melted.

\section{Results and Discussion}

\subsection{Experimental Results}

Having fabricated the furnace, it was tested in a three different ways to determine the time it takes to raise the temperature up to $660^{\circ} \mathrm{C}$ and above for melting of aluminium in each of the tests conducted. These include: No load test of the furnace, furnace with load of $30 \mathrm{~kg}$ at once test and continuous load test.

A. No load test: During this experiment the furnace was tested with the crucible empty without load of aluminum, fig. 4.1 shows the temperature of the crucible when it rose from room temperature of $28{ }^{\circ} \mathrm{C}$ to $1386{ }^{\circ} \mathrm{C}$ in 70 minutes, with the 1 litre of diesel fuel consumed. During this experiment the furnace was tested with the crucible empty without load of aluminum. This result shows that the furnace is not restricted to aluminium and can be used to melt materials with melting point up to $1386^{\circ} \mathrm{C}$.

B. With load test (batch method): The trend of temperature -time for this experiment is presented in fig. 4.2, the furnace was tested under the load of $30 \mathrm{~kg}$ at once, the load of $30 \mathrm{~kg}$ of aluminum was put in to the crucible furnace at once and tested the furnace performance, the time taken when the crucible temperature rose to the melting point of $660{ }^{\circ} \mathrm{C}$ as observed in 60 minutes while steering the aluminum for it to melt completely, this test consumed 2 litres of diesel.

C. With load test continuous method: The continuous method of melting process was adopted in order to determine the time taken to melt each kilogram of aluminum and holding time for steering the molten aluminum to ensure complete melting of aluminum. The trend of the temperature rises and drop in the crucible while adding kilogram by kilogram of aluminum in to the crucible as observed are presented in fig. 4.3. 


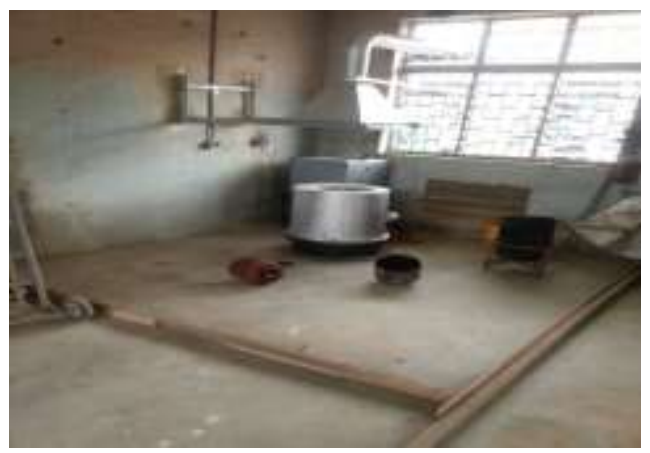

Fig. 3.3: Crucible Furnace Assembly.

\subsection{Performance Evaluation}

Electric blower was connected to the diesel pipe of the furnace and properly sealed to avoid leakage of air. The necessary diesel for firing the furnace was placed in the fuel container and the blower which supplies air is powered. Scrap metals of Aluminium of mass $30 \mathrm{~kg}$ was charged into crucible into the combustion chamber. The furnace was ignited and was covered. The diesel valve was gradually opened to enable fuel flow into the flame that was already created inside the furnace and the blower was powered and valve was adjusted until the desired air-fuel ratio was obtained that gave complete combustion. A pyrometer was used to obtain the temperature in the combustion chamber of the furnace through the opening on the cover of the furnace. The temperature in the combustion chamber was recorded at a time interval of 6 minutes. The average heating rate as well as highest temperature of the furnace was recorded and this is presented in Table 4.1. The time taken to melt Aluminium was also recorded and the melting rate was determined with equation (4.1) [14]. The furnace melting rate recorded was compared to a mini-electric arc furnace of melting rate of $21.05 \mathrm{~g} / \mathrm{mins}$ for steel/cast iron scraps obtained [14]. If there is any difference, it may be as a result of the density of steel/cast iron which is higher than that of aluminium [15].
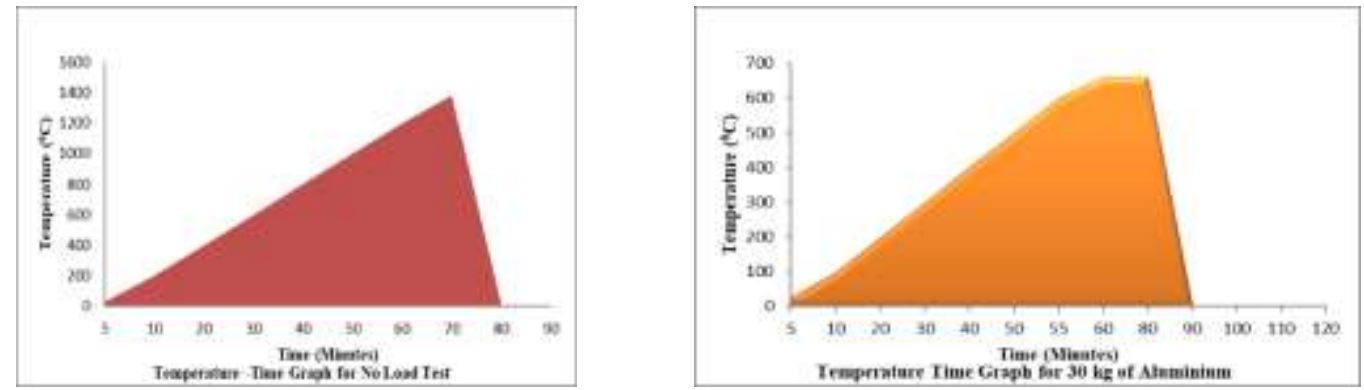

Fig. 4.1: Temperature-Time Graph for No Load. Fig. 4.2: Temperature-Time Graph for $30 \mathrm{~kg}$ of Aluminium.

$$
\text { Melting Rate }=\frac{\text { Total mass of charge }(\text { grammes })}{\text { Total time taken to melt charge }(\mathrm{mins})}=\frac{30000(\mathrm{grammes})}{66(\mathrm{mins})}=454.55 \mathrm{~g} / \mathrm{mins}
$$

This is far better than the results from literatures.

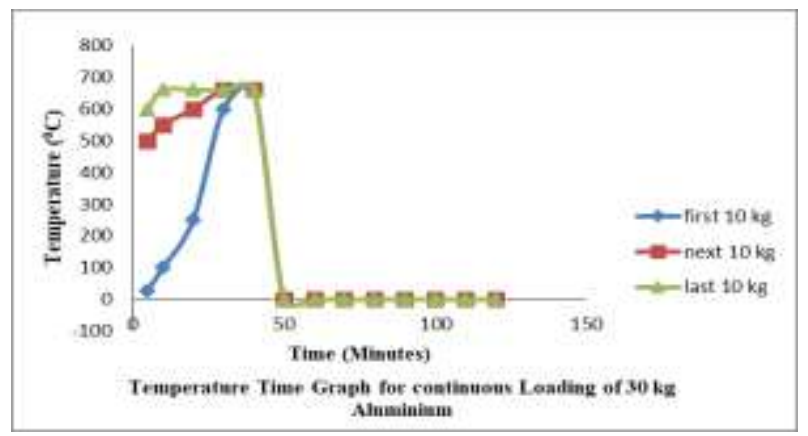

Fig. 4.3: Temperature-Time Graph for continuous loading $30 \mathrm{~kg}$ Aluminium. 


\subsection{Thermal Efficiency of the furnace}

Thermal efficiency $(\eta)$ of the furnace was determined using equation (4.2) [16]:

$$
\eta=\frac{\text { Heat required to melt aluminium }}{\text { Heat used to melt aluminium }}
$$

The value of thermal efficiency obtained was compared with those obtained by [9], [16] and [17]. with efficiencies of $10.34 \%, 11.5 \%$ and $13.72 \%$ respectively for the furnace.

$$
\eta=\frac{30000 \times 0.0279 \times(1420-28)}{27300}=\frac{294790 \mathrm{~J} / \mathrm{kg}}{27300 \mathrm{~J} / \mathrm{kg}} \times 100 \%=10.80 \%
$$

\begin{tabular}{|c|c|c|c|}
\hline$S / N$ & $\begin{array}{l}\text { Time } \\
\text { (min) }\end{array}$ & $\begin{array}{l}\text { Temp. Attained } \\
\left({ }^{\circ} \mathrm{C}\right)\end{array}$ & $\begin{array}{r}\text { Heating } \\
\text { Rate }\left({ }^{0} \mathrm{C} / \mathrm{min}\right)\end{array}$ \\
\hline 1 & 6 & 168 & 28 \\
\hline 2 & 12 & 199 & 16.6 \\
\hline 3 & 18 & 234 & 13 \\
\hline 4 & 24 & 280 & 11.7 \\
\hline 5 & 30 & 430 & 14.3 \\
\hline 6 & 36 & 628 & 17.4 \\
\hline 7 & 42 & 922 & 22 \\
\hline 8 & 48 & 1148 & 24 \\
\hline 9 & 54 & 1276 & 23.6 \\
\hline 10 & 60 & 1370 & 22.8 \\
\hline 11 & 66 & 1420 & 21.5 \\
\hline \multicolumn{3}{|c|}{ Average } & 19.54 \\
\hline
\end{tabular}

Table 4.1: Heating Rate.

The thermal efficiency compared to literatures is somehow low; it may be as a result of large energy wastage due to the type of insulator used in making the furnace wall.

\section{Conclusion}

The developed crucible furnace was fire using diesel to melt aluminium scraps of automobiles and kitchen utensils using sand casting moulds. In developing countries like Nigeria, where job opportunities are very scarce, it is not wise to allow the few operating ones to close down.

The following conclusions can also be made:

i. The crucible furnace proved to be effective for melting of aluminium and other materials with melting point below $1420^{\circ} \mathrm{C}$.

ii. This process seems too economical and time saving during operation compared to foreign ones.

iii. It can be concluded that the device is suitable for use in small scale foundries and tertiary institutions.

iv. The equipment can be used for small scale foundry workshop, hence providing employment opportunities in the Nigeria.

\section{References}

[1] R. K. Jain, "Production Technology," Manufacturing Process, Technology and Automation, vol. 2-B, Nath Market, Nai Sarak, Delhi: Romesh Chander Khanna for Khanna Publishers, 2009.

[2] I. S. Asibeluo, "Fundamentals of Foundry Technology and Forging Operations," $2^{\text {nd }}$ Ed., Agbor, Delta State, Nigeria: Cee Emmy Ventures, 2015. 
[3] S. O. Adeosun and L. O. Osoba, "Foundry Industry; A Tool for Technological Advancement in Nigeria," in Proceedings of Nigeria Metallurgical Society Conference, Federal University of Technology, Akure, 2008, pp. 1.

[4] I. S. Asibeluo and O. E. Ogwor, "Design of A 50-Kilogram Capacity Cast Iron Crucible Furnace Using Locally Available Materials," International Journal of Research in Engineering and Technology, vol. 5, no. 3, pp. 525-531, 2015.

[5] O. K. Abubakre, "Development of Aluminium Based Metal Matrix Particulate Composites (MMPC) Reinforced with Alumina, Silica and Mill Scale," Unpublished Ph.D Thesis, Submitted to the Mechanical Engineering Department, Federal University of Technology, Minna, Nigeria, 2001.

[6] J. Gupta, Elements of Fuels, Furnaces and Refractory's. 5th Ed., New Delhi: Romesh Chanda Khanna, 2008, pp. 10891458.

[7] A. A. Olalere, O. A. Dahunsi, M. A. Akintunde, and M. O. Tanimola, "Development of A Crucible Furnace Fired with Spent Engine Oil using Locally Sourced Materials," International Journal of Innovation and Applied Studies, vol. 13 no. 2, pp. 281-288, 2015.

[8] J. D. Folayan, "Design of a coal fired crucible type furnace," Undergraduate Project, Department of Mechanical Engineering, ABU Zaria.

[9] A. O. Ighodalo, G. Akue, E. Enaboifo, J. Oyedoh, "Performance Evaluation of the Local Charcoal-Fired Furnace for Recycling Aluminium," Journal of Emerging Trends in Engineering and Applied Sciences, vol. 2, no. 3, pp. 448-450, 2011.

[10] I. F. Titiladunayo and O. P. Fapetu, "Selection of Appropriate Clay for Furnace Lining in a Pyrolysis Process," Journal of Emerging Trends in Engineering and Applied Sciences, vol. 2, no. 6, pp. 938 - 945, 2011.

[11] Y. Toshikazu and M. Ryoya, "The Production of Kerosene Burning Crucible Furnace and a Lesson in Casting Aluminium," JJSTE, vol. 40, no. 22, 2012.

[12] K. K. Alaneme and S. O. Olanrewaju, "Design and Construction of a Diesel Fired Heat-Treatment Furnace," Journal of Minerals \& Materials Characterization \& Engineering, vol. 9, no. 7, pp. 581-591, 2010.

[13] C. C. Beneth and B. O. Martins, "Design and Construction of an Oil Fired Crucible Furnace," International Journal of Research and Review, vol. 5, no. 2, pp. 67-74, 2018.

[14] F. A. Oyawale and D. O. Olawale, "Design and construction of a Mini-Electric Arc Furnace," The Pacific Journal of Science and Technology, vol. 8, no. 1, 2011.

[15] P. F. Ostwald and J. Muñoz, Manufacturing Processes and Systems. 9th Ed., John Wiley \& Sons, 1997.

[16] J. O. Osarenmwinda, "Fabrication and Performance Evaluation of Oil -Fired Crucible Furnace Using Locally Sourced Materials," Int. Journal of Engineering Research and Applications, vol. 5, no. 3, pp. 29-33, 2015.

[17] S. S. Bhandari, S. B. Badadal, V. G. Kinagi, H. S. Tuljapurkar and S. H. Bansode, "Design and Fabrication of Crucible Furnaces by using Black Smithy Setup," International Journal of Engineering and Management Research, vol. 8, no. 4, pp. 131-134, 2018. 